\title{
Residential summer camp: a new venue for nutrition education and physical activity promotion
}

\author{
Alison K Ventura ${ }^{1^{*}}$ and Barry A Garst ${ }^{2}$
}

\begin{abstract}
Background: Millions of children attend residential summer camps each year. However, few studies have examined the potential of camps for obesity prevention efforts. Research in the domain of positive youth development has shown that camp programs as short as one week have both short- and long-term positive effects on self-esteem, self-efficacy and other youth outcomes. The objective of the present study was to highlight the potential of resident camps as promising venues for the promotion of healthy eating and physical activity behaviors in the children who attend.

Methods: Data for this study came from the American Camp Association 2007 Emerging Issues Survey. This survey assessed camp professionals' perspectives on a diverse array of issues, including the healthy eating and physical activity of children. Data analysis focused on responses from 247 camp professionals whose camps offered resident camp programs.

Results: Descriptive and Chi-square statistics were calculated. Ninety-two percent of camp professionals reported that the healthy eating and physical activity of campers was an "important" or "very important" issue for camps. The majority of camps reported offering vegetarian options, healthy snacks and salad bars, and allergen-free options. Additionally, $86 \%$ of camp professionals indicated that they had implemented one or more strategies to address concerns related to the unhealthy eating behaviors of children, with top strategies including increasing the availability of fruits and vegetables, increasing the availability of healthy drink options, and improving the nutritional quality of menus. Fewer camp professionals (50\%) indicated they had implemented strategies to increase children's physical activity levels, but many professionals indicated that their camp programs were inherently active and additional strategies to promote physical activity were not necessary. Associations were found between camp affiliation and food options available to campers.

Conclusions: The majority of camp professionals believe the healthy eating and physical activity of children are important issues for camps and have implemented strategies to address these issues. An important question for future research is to examine whether these strategies are effective in promoting healthy eating and physical activity behaviors in children, as well as ways that camp programs could be improved.
\end{abstract}

Keywords: Healthy eating, Physical activity, Children, Residential summer camps, Obesity prevention

\section{Background}

The diets and physical activity behaviors of American children and adolescents need improvement. Eighty-six percent of young children consume a sweetened beverage or dessert daily [1] and over $80 \%$ of 4-18-year-old children do not meet recommendations for fruit or vegetable intakes [2]. Additionally, 8-18-year-old children watch an

\footnotetext{
* Correspondence: akventura@drexel.edu

1 Department of Nutrition Sciences, College of Nursing and Health Professions, Drexel University, Philadelphia, PA, USA

Full list of author information is available at the end of the article
}

average of 4.5 hours of television daily [3] and over half of adolescents do not meet physical activity recommendations [4]. The negative impact of these concerning trends is illustrated, in part, by the increasing prevalence of obesity among children and adolescents [5].

Interventions aimed at improving children's eating and physical activity behaviors have focused on a number of contexts within which youth spend their time, including homes [6], schools [7], and community-based organizations [8]. Less attention has been paid to the potential of summer camps, despite the fact that, as an institution,

\section{Biomed Central}

(C) 2013 Ventura and Garst; licensee BioMed Central Ltd. This is an Open Access article distributed under the terms of the Creative Commons Attribution License (http://creativecommons.org/licenses/by/2.0), which permits unrestricted use, distribution, and reproduction in any medium, provided the original work is properly cited. 
summer camps rank second only to schools in the number of children who attend [9]. The American Camp Association (ACA) serves as a knowledge center for the camp community and offers the only recognized accreditation program for U.S. camps that meet up to 300 standards for health, safety, and program quality. Camps accredited by the ACA serve a diverse array of children: $90 \%$ of these camps offer financial assistance to children who are from economically deprived families or experience other hardships that may interfere with their ability to attend camp [10]. Additionally, 5\% of ACAAccredited camps specifically target youth who are at-risk, $42 \%$ target youth from economically-deprived families, and $60 \%$ target children with special medical needs [10]. Thus, summer camps provide access to a large number of children, many of whom are at higher risk for poor dietary intake and high prevalence of obesity.

The majority of summer camps in the U.S. are residential summer camps. Resident camps generally have the following characteristics: 1) sessions vary in length, 2) the program is operated and staffed by the camp, 3) supervision of individual campers is a camp responsibility, 4) campers stay overnight, and 5) camp is responsible for campers 24 hours a day [11]. Several common elements of resident camp programs make them viable settings for interventions to improve children's eating and physical activity behaviors. First, resident camps are a controlled environment where camp administrators determine the foods offered to campers at meals and the activities in which campers participate. Second, a hallmark feature of resident camps is the provision of developmentally appropriate supports and opportunities aimed at fostering skill building and personal growth for children [12]. For many children, camp provides supportive peer and adult relationships and novel resources and experiences not available in their home environments. Third, camps are sustained and immersive experiences that have the intensity and duration to have a substantial impact on children's developmental outcomes [13].

A strong body of research suggests that camp experiences as short as one week [13] can increase children's locus of control and general self-efficacy, and positive effects of camp experiences on children's psychosocial development are maintained for months [14] and years [15] beyond the camp experience. One of the first large-scale efforts to document the psychosocial outcomes of the camp experience was the ACA's National Youth Development Outcomes study, in which over 5,000 campers, staff, and parents from a representative national sample of camps were asked about the ways in which campers benefitted from their camp experience [14]. Campers, parents, and camp staff all reported significant increases in campers' self-esteem, peer relationships, independence, exploration, leadership, friendship skills, values and decisions, social comfort, and spirituality between the pre- to immediate post-camp assessments. Additionally, campers and parents reported maintenance of, or in some cases further increases in, these gains 6 months after camp. That these changes were consistent across camper, parent and camp staff reports strongly suggests the camp experience was the source of sustainability in these outcomes, and reinforce the potential of camps for positive youth development [16].

The ability of residential summer camps to promote healthy eating and physical activity behaviors in children has received a paucity of research attention. While a very small percentage of camps (1\%) are weight loss camps that specifically target obese children [17,18] most camps either focus on a specific activity or offer a broad array of activities that include aquatics, arts, and crafts, sports, environmental exploration, outdoor adventure, and academics. Whether and how these camps make an intentional effort to promote healthy eating and physical activity behaviors in their campers has not been empirically studied.

As a first step towards understanding how the residential summer camp experience may influence children's eating and physical activity behaviors, the present study explored camp professionals' perceptions of: 1) the importance of promoting healthy eating and physical activity behaviors in children; 2) the food options available at their camps; and 3) any strategies they have implemented at their camps to promote healthy eating behaviors and physical activity in their campers. This study aimed to provide a foundation for future research focused on understanding how the residential summer camp experience can be optimized to have a positive impact on the healthy eating and physical activity behaviors of children.

\section{Methods \\ Participants}

Data for this study came from the ACA 2007 Emerging Issues Survey. In November 2007, camp professionals (owners, directors, administrators; $N=2,353$ ) who were ACA members were invited to participate in an online survey $^{\mathrm{a}}$. A total of 367 surveys were completed (response rate $=16 \%)$.

\section{Survey design}

Survey questions were developed by the ACA in consultation with research experts from the ACA's Committee for the Advancement of Research and Education, which is composed primarily of university faculty from a variety of youth-related disciplines. The survey was designed to assess camp professionals' perceptions of emerging camp issues and trends. Survey questions focused on 12 issue areas: 1) Security; 2) Parent Communication; 3) Medical 
Insurance and Medication; 4) Healthy Eating and Physical Activity of Children; 5) Electronics and Social Networks; 6) Severe Weather; 7) Programming; 8) Problem Behaviors; 9) Staff Recruitment, Screening, and Training; 10) Crisis Management; 11) Outcome Evaluation; and 12) Camper Pregnancies. Camp professionals also provided data on the following demographic variables: programs offered (residential, day camp, or family programs), camp affiliation (independent for-profit, independent not-for-profit, agency, or religious), current position at camp, number of years experience in this position, gender, age group, and ethnic heritage. As a secondary analysis of de-identified data, this study was exempt from Institutional Review Board approval.

With respect to the Healthy Eating and Physical Activity of Children issue area, camp professionals were asked three questions:

1) Which of the following food options do you provide to campers?

2) In the past three years, how has your camp addressed concerns related to unhealthy eating behaviors of children?

3) In the past three years, what strategies have you tried to increase children's physical activity level at camp?

Camp professionals were provided with a variety of response options, but also allowed to select "Other" and provide a qualitative response to each question posed. Tables 1, 2 and 3 list the possible response options for Questions 1, 2 and 3, respectively. Definitions were not provided for any of the terms used (for example, "healthy eating" or "healthy snacks").

Table 1 Food options offered by camps with residential summer camp programs ${ }^{1}(n=247)$

\begin{tabular}{lll}
\hline & Percent & $\boldsymbol{n}$ \\
\hline Vegetarian & 89.1 & 220 \\
Healthy snacks & 76.5 & 189 \\
Salad bar & 70.9 & 175 \\
Other allergy-free options & 55.5 & 137 \\
Peanut-free / Soy Nut Butter & 42.1 & 104 \\
Vegan & 25.1 & 62 \\
Pork free & 22.3 & 55 \\
Portion controlled & 19.8 & 49 \\
Organic/Local & 13.8 & 34 \\
Kosher & 13.0 & 32 \\
Calorie controlled & 10.1 & 25 \\
Other & 14.2 & 35 \\
I do not offer any of the options listed above & 2.0 & 5 \\
\hline 1 Respondents could select more than one option & &
\end{tabular}

${ }^{1}$ Respondents could select more than one option.

\section{Statistical analysis}

For the present study, only data from camp professionals whose organizations offered a residential summer camp program were analyzed $(n=247)$. Additionally, data analysis focused on survey items that pertained to the healthy eating and physical activity of children and the demographic characteristics of respondents. Quantitative data were analyzed using SPSS version 20 (Chicago, IL). Descriptive statistics were calculated to summarize participant responses. Chi-square tests were used to examine the association between camp affiliation and healthy eating and physical activity offerings at camps. A significance level of $p<.05$ was used for all 2-sided tests of no association. Qualitative data from open-ended questions were sorted into thematic categories using constant comparison within the framework of grounded theory [19].

\section{Results}

\section{Sample characteristics}

Camp professionals reported that their camps served an average of $1,060 \pm 1,658$ (range $=61$ to 21,940 ) children annually. Combined, the camps participating in this survey served a total of 259,598 children per year. Table 4 presents demographic information for the sample. Equal proportions of male and female camp professionals participated in this survey. Thirty percent of camp professionals were between 45 and 54 years of age and 95\% were white. Approximately two-thirds (62.3\%) of respondents were camp directors. Thirty-nine percent of camps were affiliated with an agency, (e.g., YMCA or Boy/Girl Scouts), while the remaining $61 \%$ were dispersed among independent-for-profit (18.2\%), independent not-for-profit

Table 2 Strategies used by camps with residential summer camp programs to address unhealthy eating behaviors of children ${ }^{1}(n=247)$

\begin{tabular}{lll}
\hline & Percent & $\boldsymbol{n}$ \\
\hline Increased fruits and vegetables & 73.3 & 181 \\
Increased healthy drink options (milk, water) & 55.1 & 136 \\
Re-designed daily menus to incorporate healthier foods & 55.1 & 136 \\
Reduced sweets/sugary foods & 45.7 & 113 \\
Reduced fried foods & 43.3 & 107 \\
Provided more healthy food options in canteen & 36.4 & 90 \\
Reduced candy, soda, and other "junk food" in canteen & 33.2 & 82 \\
Prohibited care packages containing food & 27.1 & 67 \\
Offer low/no fat alternatives where possible & 16.6 & 41 \\
Served smaller meal portions & 6.9 & 17 \\
Encouraged small-portion meals and/or healthy snacks & 3.6 & 9 \\
Other & 13.0 & 32 \\
No new strategies have been used & 13.8 & 34 \\
\hline Respondents could select more than one option. & &
\end{tabular}

${ }^{1}$ Respondents could select more than one option. 
(22.7\%), or religious (19.4\%) affiliations. While all camps included in this study offered a residential program, many also offered day camps, trip or travel camps, and family camps.

\section{Perceptions of the importance of healthy eating and physical activity}

Camp professionals were asked to rate the importance of the healthy eating and physical activity of campers based on a 4-point Likert scale ( 1 = very unimportant; 2 = unimportant; 3 =important; 4 =very important). Forty-one percent $(n=102)$ of camp professionals reported that the healthy eating and physical activity of campers was "very important," whereas 51\% $(n=126)$ of respondents said that healthy eating and physical activity of children was "important" and $8 \%(n=19)$ reported that this issue was "unimportant" or "very unimportant." Camp professionals' ratings of the importance of healthy eating and physical activity of children were not associated with camp affiliation.

\section{Food options at camps}

Table 1 presents camp professionals' responses to the question: "Which of the following food options do you provide to campers?" Camp professionals were provided with a list possible options, of which more than one could be selected. The majority of camp professionals reported offering vegetarian options, healthy snacks, salad bars, and allergen-free options. Camp professionals who indicated "Other" $(14.2 \%, n=35)$ provided additional qualitative information about their food options. The majority of these responses centered around three themes: 1) providing options for celiac disease, lactose intolerance, diabetes and other medical conditions $(n=30) ; 2)$ providing low-salt or -sugar meal options $(n=9)$; and 3) willingness to tailor food options to campers' individual needs $(n=13)$.

A significantly higher percentage $(26.7 \%, n=12)$ of professionals from independent for-profit camps reported that their camp offered local/organic food options compared to professionals from agency camps $\left(8.3 \%, n=8 ; X^{2}=8.7\right.$, $p=.033$ ). Significantly greater proportions of professionals from independent not-for-profit camps reported that their camp offered calorie-controlled meals $(23.2 \%, n=13)$ compared to professionals from agency camps $(5.2 \%, n=5$; $\left.X^{2}=13.8, p=.003\right)$. A significantly greater proportion of professionals from independent not-for-profit camps also reported that their camp offered portion-controlled meals (35.7\%, $n=20$ ) compared to professionals from agency $(12.5 \%, n=12)$ and independent for-profit camps $(8.9 \%$, $\left.n=4 ; X^{2}=17.0, p<.001\right)$.

\section{Strategies to address unhealthy eating behaviors of children}

Table 2 presents camp professionals' responses to the question: "In the past three years, how has your camp addressed concerns related to the unhealthy eating behaviors of children?" Camp professionals were provided with a list possible options, of which more than one could be selected. Approximately $86 \%$ of camp professionals indicated that they had implemented one or more strategies to address concerns related to unhealthy eating behaviors of children. Top strategies included increasing the availability of fruits and vegetables (73.3\%, $n=181$ ), increasing the availability of healthy drink options $(55.1 \%, n=136)$, and redesigning daily menus to incorporate healthier foods $(55.1 \%, n=136)$.

Camp professionals who indicated "Other" (13.0\%, $n=32$ ) provided additional qualitative information. Responses centered around four themes: 1) specific strategies focused on the quality and type of food served, including increased purchase of local or organic foods and increased availability of whole grains $(n=16) ; 2)$ food options have always been healthy, thus new strategies were not needed $(n=12)$; 3 ) prohibition of certain foods in care packages or canteens/camp stores $(n=10)$; and 4) adoption of nutrition education programing $(n=8)$. Responses related to increased nutrition education included offering both formal and non-formal education in the form of nutrition workshops and electives or encouraging counselors to model healthy eating habits.

A significantly higher percentage $(31.1 \%, n=14)$ of professionals from independent for-profit camps reported

Table 3 Ways in which camps have tried to increase children's physical activity level at camp ${ }^{1}(n=247)$

\begin{tabular}{lll}
\hline & Percent & $\boldsymbol{n}$ \\
\hline Encouraged staff to be more physically active in order to set a better example for the campers & 39.3 & 97 \\
Increased the frequency of program options that incorporate vigorous physical activity & 26.7 & 16.6 \\
Provided coaching/instruction to campers on the value of physical activity & 14.2 \\
Required participation in programs that incorporate vigorous physical activity & 4.9 & 35 \\
Decreased the frequency of any minimally physically active program options & 6.1 & 12 \\
Other & 50.0 & 15 \\
No new strategies have been used & 123 \\
\hline
\end{tabular}

${ }^{1}$ Respondents could select more than one option. 
Table 4 Characteristics of camp professionals participating in the 2007 American Camp Association Emerging Issues Survey $(n=247)$

\begin{tabular}{|c|c|c|}
\hline & Percent & $n$ \\
\hline \multicolumn{3}{|l|}{ Gender } \\
\hline Male & 49.4 & 122 \\
\hline Female & 47.8 & 118 \\
\hline No Response & 2.8 & 7 \\
\hline \multicolumn{3}{|l|}{ Age group } \\
\hline $18-24$ years & 1.2 & 3 \\
\hline 25-34 years & 23.5 & 58 \\
\hline $35-44$ years & 27.9 & 69 \\
\hline $45-54$ years & 30.0 & 74 \\
\hline $55-64$ years & 15.0 & 37 \\
\hline$>65$ years & 1.2 & 3 \\
\hline No response & 1.2 & 3 \\
\hline \multicolumn{3}{|l|}{ Race/Ethnicity } \\
\hline Black & 0.4 & 1 \\
\hline White & 94.7 & 234 \\
\hline Other (e.g. multiracial) & 4.9 & 12 \\
\hline \multicolumn{3}{|l|}{ Years of experience in current camp position } \\
\hline$<2$ years & 11.7 & 29 \\
\hline 2 to 5 years & 25.9 & 64 \\
\hline 6 to 10 years & 24.3 & 60 \\
\hline$>10$ years & 38.1 & 94 \\
\hline \multicolumn{3}{|l|}{ Position at Camp } \\
\hline Camper owner or operator & 11.3 & 28 \\
\hline Camp director & 62.3 & 154 \\
\hline Agency executive & 15.4 & 38 \\
\hline Camp administrative staff ${ }^{1}$ & 9.3 & 23 \\
\hline Other & 1.6 & 4 \\
\hline \multicolumn{3}{|l|}{ Camp Affiliation } \\
\hline Agency (e.g. YMCA, Girl or Boy Scouts, Camp Fire) & 38.9 & 96 \\
\hline Independent for-profit & 18.2 & 45 \\
\hline Independent not-for-profit & 22.7 & 56 \\
\hline Municipality or government & 0.8 & 2 \\
\hline Religiously affiliated & 19.4 & 48 \\
\hline \multicolumn{3}{|l|}{ Type of Program Offered ${ }^{2}$} \\
\hline Residential camp & 100.0 & 247 \\
\hline Day camp & 30.8 & 76 \\
\hline Trip/travel camp & 32.0 & 79 \\
\hline Outdoor/environmental education center & 29.1 & 72 \\
\hline Conference/retreat center & 37.2 & 92 \\
\hline Day use programs & 27.5 & 68 \\
\hline Family camp & 36.8 & 91 \\
\hline
\end{tabular}

${ }^{1}$ Assistant director, program director, business manager, etc.

${ }^{2}$ Respondents could select more than one option. that their camp "offered low/no fat alternatives where possible" compared to professionals from religiously affiliated camps $\left(8.3 \%, n=4 ; X^{2}=9.9, p=.020\right)$. No other associations between affiliation and strategies to address unhealthy eating behaviors of children were found.

\section{Promotion of physical activity at camps}

Table 3 presents camp professionals' responses to the question: "In the past three years, what strategies have you tried to increase children's physical activity level at camp?" Camp professionals were provided with a list possible options, of which more than one could be selected. Approximately fifty percent $(n=123)$ of camp professionals indicated that they had implemented one or more strategies to increase children's physical activity levels. The strategy with the highest endorsement $(39.3 \%, n=97)$ was "encouraging staff to be more physically active in order to set a better example for the campers." Eight percent $(n=20)$ of camp professionals noted that their camp program has always included many opportunities for physical activity, with several also indicating that they did not feel strategies for further increasing children's levels of physical activity were necessary.

A significantly higher percentage $(23.2 \%, n=13)$ of professionals from independent not-for-profit camps reported that their camp "required children participate in programs that incorporate physical activity" compared to professionals from agency camps $\left(6.2 \%, n=5 ; X^{2}=\right.$ 9.4, $p=.025$ ). No other associations between affiliation and strategies to increase physical activity of children were found.

\section{Discussion}

Residential summer camps serve millions of children each year [10], and have been shown to have a positive impact on children's development [16]. Previous research suggests the summer months may be a time when children are more vulnerable to inactivity [20,21] and unhealthy eating behaviors [21]. Children also tend to have higher gains in BMI during the summer months compared to the school year [22]. We propose that resident camps have the potential to reverse these trends given their duration, intensity, and provision of developmentally appropriate supports and opportunities. However, more research is needed to understand the effects resident camps currently have on children's health behaviors, and the ways in which camp programs can be improved to have positive short- and long-term effects on children's eating, physical activity, and weight status.

The present study illustrated that the majority of camp professionals believe the healthy eating behaviors and physical activity of children is an important issue for camps. These findings are promising because they show that camp professionals value the promotion of healthy eating behaviors and physical activity in their campers 
and are taking measures to actively encourage these behaviors at camp. Research on factors that contribute to children's health outcomes in other settings suggests that the strategies camp professionals reported would be effective in promoting healthy behaviors. For example, availability of fruits and vegetables is one of the strongest predictors for children's fruit and vegetable intakes in both home- and school-based settings [23-25] and repeated exposure to healthy foods promotes acceptance [26-28]. Additionally, availability of physical activity opportunities, parents' logistic support for physical activity, and parent modeling of physically active behaviors are all associated with higher levels of physical activity in chidren [29-32]. Thus, the findings that over $70 \%$ of camp professionals reported increasing the availability of fruits and vegetables and over $25 \%$ reported increasing camp staff modeling of physical activity and frequency of physically active programing over the past three years suggests that camps are providing children with opportunities to consume healthful foods and participate in physical activity in a supportive and encouraging environment.

Previous research suggests that many of the food options that camp professionals indicated were available at their camps would also promote healthful dietary patterns for campers. For example, almost $90 \%$ of camps offer vegetarian meals and $25 \%$ offer vegan meals, both of which have been shown to promote lower intakes of cholesterol, saturated fat and total fat, and higher intakes of vegetables, fruits and fiber for children and adolescents $[33,34]$. Additionally, the majority of camps reported offering healthy snacks, which may contribute positively to intake of key nutrients and lower risk for obesity [35]. Other healthy options that received far fewer endorsements were organic/local foods and portion/calorie controlled meals. Both would be beneficial to promote in camp settings given evidence for health benefits of organic foods [36], and the potential of portion/calorie controlled meals for promotion of age-appropriate energy intake [37,38].

A limitation of these data is that they represent camp professionals' perceptions. Camp professionals reported implementing a number of strategies to promote healthy eating and physical activity in children, but the fidelity to which these strategies were implemented and the quality of these changes is unknown. For example, we do not have data to determine whether camp professionals that reported redesigning their menus did so under the guidance of a registered dietician or whether the healthy eating and physical activity opportunities reported by these camp professionals were effective in influencing behavior within a camp setting. Limited research in other samples suggests that camp is effective in promoting physical activity in the short-term. Children attending both day and resident camps meet or exceed physical activity guidelines recommended by the United
States Department of Health and Human Services [39,40], and children attending summer camps are more physically active than children who do not attend camps [21]. However, further research is needed to evaluate what children are eating and how much physical activity children are participating in at camps, as well as whether these behaviors are sustained or changed - for better or worse - after the camp experience.

Camp affiliation was associated with camp professionals' reports of food options available to campers. Specifically, a greater number of independent for-profit camps offered local/organic food compared to agency camps and added low/no fat alternatives compared to religiously affiliated camps. Additionally, a greater number of independent notfor-profit camps endorsed restrictive food options including calorie- and portion-controlled meals compared to agency and independent for-profit camps.

These associations may reflect differences in the resources available to camps of differing affiliations. Independent for-profit camps typically charge higher tuition than other types of camps, thus can afford a higher level of expenses. In 2008, ACA-Accredited independent forprofit camps reported an average of $\$ 153,790$ in food and related expenditures, whereas agency, independent not-for-profit, and religious camps reported approximately $\$ 109,900, \$ 95,445$, and $\$ 74,664$ in food and related expenses, respectively [41]. Thus, independent for-profit camps have higher food budgets that may allow for local/organic foods, low/no fat alternatives and other healthier, but more expensive food options. Additionally, in 2009, independent for-profit camps reported paying a significantly higher weekly wage to their Food Service Director/Supervisor compared to camps of other affiliations [42], which may suggest that the individuals in charge of food-related decisions at independent for-profit camps have more education, training, and experience, making them better equipped to plan healthy menus.

Differences in resource availability are especially concerning when characteristics of the youth/families served by camps of differing affiliations are taken into consideration. Eighty-nine percent of children attending independent for-profit camps are from high income families [41], thus these families may already have the resources and education to provide their children with healthy diets and opportunities to be physically active. In contrast, $80 \%$ and $67 \%$ of agency and independent notfor-profit camps serve youth from low-income families, and 41 and $44 \%$ serve youth from families in poverty (compared to less than 10\% of independent for-profit camps) [41]. Thus, agency and independent not-for-profit camps are serving youth at higher risk for poor nutrition, inactivity and obesity, but these types of camps may have fewer resources available to promote healthy eating and physical activity opportunities. These camps may benefit 
from greater access to resources that allow them to provide the same diet quality and physical activity opportunities as camps that serve higher income families. These camps may also need strategies for securing healthy food resources. These strategies could include guidance related to how to ask donors for healthy options or how maximize the healthfulness of their menu within the constraints of their food budgets or food donations.

A recent statement from the American Academy of Pediatrics (AAP) Council on School Health provided recommendations for creating healthy camp experiences [43]. Within this statement, the AAP stressed that camp communities should promote healthy lifestyles for children by: 1) offering foods that follow federal guidelines for school nutrition, 2) encouraging staff to model healthful behaviors for campers, 3) limiting food used as reward, 4) ensuring children obtain at least 30 minutes of physical activity daily, and 5) offering water instead of sugar-sweetened beverages, including sports drinks [43]. Although the present study suggests that many camps are already following some or all of these recommendations, policies do not currently exist to ensure that all camps embrace these practices. Findings from this and future studies may serve as an important basis for the development of such policies. Policy-level changes could also aim to reduce disparity between offerings at forprofit and not-for-profit or agency camps by providing additional subsidies or supports to camps that serve children at higher risk for obesity. Camps are currently eligbile to participate in the USDA's Summer Food Service Program [44], but participation rates are low [45]; future research supporting the need for improved nutrition options at camps that reach underserved populations may help increase awareness and participation in such programs and could also help guide adaptations to the USDA's Summer Food Service Program to ensure that it fits camps' needs. Camps are promising venues for the promotion of healthy eating and physical activity behaviors, and future research will serve to elucidate the particular ways in which this promotion should occur to optimize health outcomes for the children who attend.

These data are not without limitations. As noted above, these data are self-reported and reflect the perceptions of camp professionals. Another limitation of these data is the low response rate (16\%), which is comparable to what is often seen with web-based survey designs $[46,47]$, but may limit the generalizability of our findings. Unfortunately, we do not have demographic information for non-respondents, thus cannot compare respondents to non-respondents to assess whether our sample was biased. Further research is needed to understand whether our findings are representative of the greater population of camp professionals and camps.

\section{Conclusions}

Residential summer camps reach a large number of youth at at time when they are susceptible to inactivity, poor diet quality, and accelerated weight gain. The idea that structured summer programs such as resident camps can promote healthy eating and physical activity behaviors in children is not new [48], but has received little attention when compared to research focused on other youth-serving organizations.

We propose that resident camps may be particularly effective sites for obesity prevention efforts because camp programs are relatively short-term compared to school-based interventions, but have been shown to have the duration, intensity and positive supports to instill meaningful and lasting impact on children's development. Additionally, camp staff may be particularly influential models for campers' eating and physical activity behaviors because camp staff are perceived by children to be both a peer and an authority figure, creating a relationship unique to that of other caregivers [16]. Thus, children may be especially receptive to camp programs and camp staffs' behaviors in ways that are distinct from other youth serving organizations.

Residential camps have been shown to be effective sites for prevention within other domains of youth development including reduction of anxiety [49] and reduction of camper injuries and illness [50]. Additionally, policy-level changes related to implementation of structured summer programs have been effectively used to counter issues such as summer learning decline [51]. We believe camp programs can be used in a similar manner to promote healthy eating and physical activity behaviors and reduce children's risk for obesity, but whether the unique environment of camps can be effectively used in this capacity is an important question for future research. The present study illustrated that camps are interested and invested in this issue. Further research is needed to fully understand the current impact camps have on children's health behaviors and the ways in which camp programs and policies related to camp programs can be futher improved to promote health and prevent obesity.

\section{Endnote}

a Survey results can be accessed at: http://www.surveymonkey.com/sr.aspx?sm=GZn6UTvY94DT78dVly XgQ7Lefq78E_2b4jL6SBgIRmomg_3d.

\section{Competing interests}

Both authors declare that they have no competing interests.

\section{Authors' contributions}

BAG was involved in the acquisition of the data. AKV analyzed and interpreted the data. Both authors drafted the manuscript and critically revised it for important intellectual content. Both authors read and approved the final manuscript. 


\section{Acknowledgements}

The authors would like to thank and acknowledge the American Camp Association (ACA) and the ACA's Committee for the Advancement of Research and Evaluation (CARE) for providing access to the data used for the analysis provided in this study.

\section{Author details}

${ }^{1}$ Department of Nutrition Sciences, College of Nursing and Health Professions, Drexel University, Philadelphia, PA, USA. ${ }^{2}$ American Camp Association, Martinsville, IN, USA.

Received: 7 January 2013 Accepted: 17 May 2013

Published: 24 May 2013

\section{References}

1. Fox MK, Condon E, Briefel RR, Reidy KC, Deming DM: Food consumption patterns of young preschoolers: are they starting off on the right path? J Am Diet Assoc 2010, 110:S52-S59.

2. Krebs-Smith SM, Guenther PM, Subar AF, Kirkpatrick SI, Dodd KW: Americans do not meet federal dietary recommendations. J Nutr 2010 140:1832-1838.

3. Rideout VJ, Foehr UG, Roberts DF: Generation M2: Media in the Lives of 8- to 18-Year-Olds. Kaiser Family Foundation; 2010:1-85. http:// kaiserfamilyfoundation.files.wordpress.com/2013/04/8010.pdf.

4. Child Trends: Vigorous Physical Activity by Youth. 2012. http://www. childtrendsdatabank.org/?q=node/134

5. Ogden CL, Carroll MD, Kit BK, Flegal KM: Prevalence of obesity and trends in body mass index among US children and adolescents, 1999-2010. JAMA 2012, 307:483-490

6. Knowlden AP, Sharma M: Systematic review of family and home-based interventions targeting pediatric overweight and obesity. Obes Rev 2012 13:499-508

7. Safron M, Cislak A, Gaspar T, Luszczynska A: Effects of school-based interventions targeting obesity-related behaviors and body weight change: a systematic umbrella review. Behav Med 2011, 37:15-25.

8. Branscum P, Sharma M: After-school based obesity prevention interventions: a comprehensive review of the literature. Int J Environ Res Public Health 2012, 9:1438-1457.

9. Van Slyck AA: A Manufactured Wilderness: Summer Camps and the Shaping of American Youth (1890-1960). Minneapolis, MN: University of Minnesota Press; 2006.

10. Camp Trends Fact Sheet: Camp Trends Fact Sheet. http://www.acacamps. org/media-center/camp-trends/fact]. Accessed on: 2012 Oct 21.

11. American Camp Association: Accreditation Process Guide. 2012. Martinsville, IN: American Camp Association; 2012.

12. Garst BA, Browne LP, Bialeschki M: Youth development and the camp experience. New Dir Youth Dev 2011, 130:73-87.

13. Sekine A: The effect of camp experience upon the locus of control and general self-efficacy of school children. Bull Inst Health Sport Sci 1994, 17:177-183.

14. American Camp Association: Directions: Youth Development Outcomes of the Camp Experience. Martinsville, IN: American Camp Association; 2005:1-24.

15. Bialeschki M, Lyons KT, Thompson AK: Four Years at Morry's Camp: a Longitudinal Study of Youth Development Outcomes of the Morry's Camp Experience. Martinsville, IN: American Camp Association; 2006.

16. Bialeschki MD, Henderson KA, James PA: Camp experiences and developmental outcomes for youth. Child Adolesc Psychiatr Clin N Am 2007, 16:769-788. vi.

17. Kelly KP, Kirschenbaum DS: Immersion treatment of childhood and adolescent obesity: the first review of a promising intervention. Obes Rev 2010, 12:37-49.

18. Huelsing J, Kanafani N, Mao J, White NH: Camp Jump Start: effects of a residential summer weight-loss camp for older children and adolescents. Pediatrics 2010, 125:e884-e890.

19. Charmaz K: Grounded theory: Objectivist and constructivist methods. In Handbook of Qualitative Research. Edited by Denzin NK, Lincoln YS. Thousand Oaks, CA: Sage Publications Inc; 2000.

20. Carrel AL, Clark RR, Peterson S, Eickhoff J, Allen DB: School-based fitness changes are lost during the summer vacation. Arch Pediatr Adolesc Med 2007, 161:561-564.
21. Tovar A, Lividini K, Economos CD, Folta S, Goldberg J, Must A: School's out: what are urban children doing? The Summer Activity Study of Somerville Youth (SASSY). BMC Pediatr 2010, 10:16.

22. von Hippel PT, Powell B, Downey DB, Rowland NJ: The effect of school on overweight in childhood: gain in body mass index during the school year and during summer vacation. Am J Public Health 2007, 97:696-702.

23. Patrick $H$, Nicklas TA: A review of family and social determinants of children's eating patterns and diet quality. J Am Coll Nutr 2005, 24:83-92.

24. Denney-Wilson E, Crawford D, Dobbins T, Hardy L, Okely AD: Influences on consumption of soft drinks and fast foods in adolescents. Asia Pac J Clin Nutr 2009, 18:447-452.

25. Holsten JE, Deatrick JA, Kumanyika S, Pinto-Martin J, Compher CW: Children's food choice process in the home environment, A qualitative descriptive study. Appetite 2012, 58:64-73.

26. Hausner H, Hartvig DL, Reinbach HC, Wendin K, Bredie WLP: Effects of repeated exposure on acceptance of initially disliked and liked Nordic snack bars in 9-11 year-old children. Clin Nutr 2012, 31:137-143.

27. Cooke $L$ : The importance of exposure for healthy eating in childhood: a review. J Hum Nutr Diet 2007, 20:294-301.

28. Anzman-Frasca S, Savage JS, Marini ME, Fisher JO, Birch LL: Repeated exposure and associative conditioning promote preschool children's liking of vegetables. Appetite 2012, 58:543-553.

29. Sallis JF, Alcaraz JE, Mckenzie TL, Howell MF: Predictors of change in children's physical activity over 20 months: variations by gender and level of adiposity. Am J Prev Med 1999, 16:222-229.

30. Davison KK, Cutting TM, Birch LL: Parents' activity-related parenting practices predict girls' physical activity. Med Sci Sports Exerc 2003, 35:1589-1595.

31. Trost SG, Kerr LM, Ward DS, Pate RR: Physical activity and determinants of physical activity in obese and non-obese children. Int J Obes Relat Metab Disord 2001, 25:822-829.

32. Vilhjalmsson $\mathrm{R}$, Thorlindsson T: Factors related to physical activity: a study of adolescents. Soc Sci Med 1998, 47:665-675.

33. Perry CL, McGuire MT, Neumark-Sztainer D, Story M: Adolescent vegetarians: how well do their dietary patterns meet the healthy people 2010 objectives? Arch Pediatr Adolesc Med 2002, 156:431-437.

34. Larsson $\mathrm{CL}$, Johansson GK: Young Swedish vegans have different sources of nutrients than young omnivores. J Am Diet Assoc 2005, 105:1438-1441.

35. Larson N, Story M: A review of snacking patterns among children and adolescents: What are the implications of snacking for weight status? Child Obes 2013, 9:104-115.

36. Smith-Spangler C, Brandeau ML, Hunter GE, Bavinger JC, Pearson M, Eschbach PJ, Sundaram V, Liu H, Schirmer P, Stave C, Olkin I, Bravata DM: Are organic foods safer or healthier than conventional alternatives?: A systematic review. Ann Intern Med 2012, 157:348-366.

37. Fisher JO, Liu Y, Birch LL, Rolls BJ: Effects of portion size and energy density on young children's intake at a meal. Am J Clin Nutr 2007, 86:174-179.

38. Savage JS, Fisher JO, Marini M, Birch LL: Serving smaller age-appropriate entree portions to children aged 3-5 y increases fruit and vegetable intake and reduces energy density and energy intake at lunch. Am J Clin Nutr 2012, 95:335-341.

39. Hickerson BD, Henderson KA: Children's summer camp-based physical activity. Camping Magazine 2010

40. U S Department of Health Human Services: 2008 Physical Activity Guidelines for Americans. Washington, D.C.: U.S. Government Printing Office; 2008

41. American Camp Association: ACA 2008 Business Operations Profile Study. 2008. http://www.acacamps.org/research/improve/budget-finance.

42. American Camp Association: Camp Compensation and Benefits Report. 2010 http://www.acacamps.org/research/camp-compensation-and-benefitsreport-2010.

43. Council on School Health: Policy Statement - Creating Healthy Camp Experiences. Pediatrics 2011, 127:794-799.

44. US Department of Agriculture - Summer Food Service Program. http://www. acacamps.org/summer-feeding-program]. Accessed on: 2013 Mar 26.

45. 2011 Emerging Issues Survey Results. http://www.acacamps.org/sites/default/ files/images/research/improve/El\%20all\%20results\%20\%28wozip\%2911.pdf]. Accessed on: 2013 Mar 26

46. Fan $W$, Yan Z: Factors affecting response rates of the web survey: $A$ systematic review. Computers in Human Behavior 2010, 26:132-139. 
47. Manfreda KL, Bosnjak M, Berzelak J, Haas I, Vehovar V: Web surveys versus other survey modes. Int J Market Res 2008, 50:79-104.

48. Jago R, Baranowski T: Non-curricular approaches for increasing physical activity in youth: a review. Prev Med 2004, 39:157-163.

49. Ehrenreich-May J, Bilek EL: Universal prevention of anxiety and depression in a recreational camp setting: An initial open trial. Child \& Youth Care Forum 2011, 40:435-455.

50. Erceg LE, Garst BA, Powell GM: An injury and illness surveillance program for children and staff: Improving the safety of youth settings. J Park Rec Admin 2011, 27:121-132.

51. Fairchild R, McLaughlin B, Costigan BP: How did you spend your summer vacation? What public policies do (and don't do) to support summer learning opportunities for all youth. Afterschool Matters Occasional Paper Series 2007, 8:1-31.

doi:10.1186/1479-5868-10-64

Cite this article as: Ventura and Garst: Residential summer camp: a new venue for nutrition education and physical activity promotion.

International Journal of Behavioral Nutrition and Physical Activity 2013 10:64.

\section{Submit your next manuscript to BioMed Central and take full advantage of:}

- Convenient online submission

- Thorough peer review

- No space constraints or color figure charges

- Immediate publication on acceptance

- Inclusion in PubMed, CAS, Scopus and Google Scholar

- Research which is freely available for redistribution 